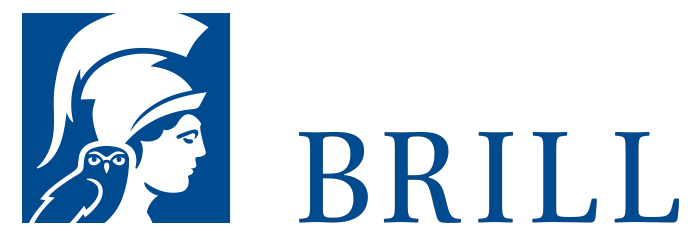

\section{Demografische Entwicklung, Klimawandel, Peak Oil Kraftwerkstechnik mit $\mathrm{CO}_{2}$ - Rückhaltung}

Antworten der Raum-, Stadt- und Verkehrsplanung

Anforderungen an Stoffdatenmodelle

Authors: Roland Span and Felix Huber

Die Nordrhein-Westfälische Akademie der Wissenschaften und der Künste ist eine Vereinigung der führenden Forscherinnen und Forscher des Landes. Sie wurde 1970 als Nachfolgeeinrichtung der Arbeitsgemeinschaft für Forschung des Landes Nordrhein-Westfalen gegründet. Die Akademie ist in drei wissenschaftliche Klassen für Geisteswissenschaften, für Naturwissenschaften und Medizin sowie für Ingenieur- und Wirtschaftswissenschaften und in eine Klasse der Künste gegliedert.

Mit Publikationen zu den wissenschaftlichen Vorträgen in den Klassensitzungen, zu öffentlichen Veranstaltungen und Symposien will die Akademie die Fach- und allgemeine Öffentlichkeit über die Arbeiten der Akademie und ihrer Forschungsstellen informieren.

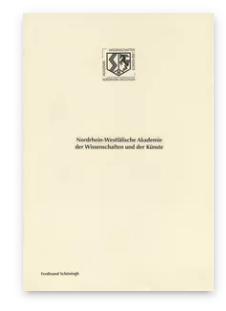

Pages: 6o Seiten, 37 farb.

Abb.

Language:

German

Subjects:

Economics \&

Political Science,

Social Sciences

Publisher: Brill |

Schöningh

Series:

Nordrhein Westfälische

Akademie der

Wissenschafte - Ingenieurund

Wirtschaftswissenschaften, Volume: 33

E-Book (PDF)

Released online:

og Mar 2020

ISBN: 978-3-

657-77367-1

List price

USD \$40.00

Paperback

Publication date: 26 Oct 2011

ISBN: 978-3-

506-77367-8

List price

USD \$40.00 
For more information see brill.com

Order information: Order online at brill.com +44330 333 0049 | customerservices@brill.com Submission information: brill.com/authors

Titles published by Brill | Fink, Brill | mentis or Brill | Schöningh: +49(o)715413279216| brill@brocom.de 